\title{
Treponema lecithinolyticum sp. nov., a small saccharolytic spirochaete with phospholipase A and $C$ activities associated with periodontal diseases
}

\author{
C. Wyss, ${ }^{1}$ B.-K. Choi, ${ }^{2,3}$ P. Schüpbach, ${ }^{1}$ A. Moter, ${ }^{2}$ B. Guggenheim ${ }^{1}$ \\ and U. B. Göbel ${ }^{2}$
}

Author for correspondence: C. Wyss. Tel: +411634 3322. Fax: +411 6344310.
e-mail: wyss.c@zzmk.unizh.ch

1 Institut für Orale Mikrobiologie und Allgemeine Immunologie, Zentrum für Zahn-, Mundund Kieferheilkunde der Universität Zürich, Plattenstrasse $11, \mathrm{CH}-8028$ Zürich, Switzerland

2 Universitätsklinikum Charité, Institut für Mikrobiologie und Hygiene, Dorotheenstrasse 96, D-10117 Berlin, Germany

3 Department of Oral Biology, Yonsei University College of Dentistry, Seoul, Republic of Korea

\begin{abstract}
Strong phospholipase A (PLA) and phospholipase C (PLC) activities as potential virulence factors are the outstanding characteristics of eight strains of small oral spirochaetes isolated from deep periodontal lesions. By qualitative dotblot DNA-DNA hybridization and 16S rDNA sequence comparison, these spirochaetes form a distinct phylogenetic group, with Treponema maltophilum as its closest cultivable relative. Growth of these treponemes, cells of which contain two endoflagella, one at each pole, was autoinhibited by the PLAmediated production of lysolecithin unless medium OMIZ-Pat was prepared without lecithin. $\mathrm{N}$-Acetylglucosamine was essential and $\mathrm{D}$-ribose was stimulatory for growth. All isolates were growth-inhibited when $1 \%$ foetal calf serum was added to the medium. Growth on agar plates supplemented with human erythrocytes produced haemolysis. In addition to PLA and PLC, the new isolates displayed strong activities of alkaline and acid phosphatases, $\beta$-galactosidase, $\beta$-glucuronidase, $N$-acetyl- $\beta$-glucosaminidase and sialidase, intermediate activities of C4- and C8-esterases, naphthol phosphohydrolase and $\alpha$-fucosidase and a distinctive $30 \mathrm{kDa}$ antigen detectable on Western blots. This phenotypically and genotypically homogeneous group is proposed as a novel species, Treponema lecithinolyticum sp. nov., with isolate OMZ 684 ${ }^{\top}$ designated as the type strain. A molecular epidemiological analysis using a T. lecithinolyticum-specific probe showed this organism to be associated with affected sites when compared with unaffected sites of periodontitis patients. This association was more pronounced in patients with rapidly progressive periodontitis than in those with adult periodontitis.
\end{abstract}

Keywords: Phospholipase, periodontal disease, phylogeny, cultivation, virulence

\section{INTRODUCTION}

Dental plaque is implicated in the development of periodontal diseases and is thought to induce tissue damage both by direct bacterial effectors and by

Abbreviations: AP, adult periodontitis; Bis-BODIPY, 1,2-bis-(4,4-difluoro5,7-dimethyl-4-bora-3a,4a-diaza-s-indacene-3-undecanoyl)-sn-glycero-3phosphocholine; MU-NANA, 4-methylumbelliferyl $\mathrm{N}$-acetylneuraminic acid; MU-PC, 4-methylumbelliferyl phosphocholine; PLA, phospholipase A; PLC, phospholipase C; pNP-PC, p-nitrophenylphosphorylcholine; RPP, rapidly progressive periodontitis.

The EMBLGenBank accession numbers for the 16S rRNA sequences of strains OMZ 684 ${ }^{\top}$ and OMZ 702 are X89139 and AJ007740. misguided host response mechanisms (Holt \& Bramanti, 1991; Socransky \& Haffajee, 1991). The search for aetiological agents of periodontitis has resulted in the identification of some 300 bacterial species in dental plaque by cultural methods (Moore $e t$ al., 1991). However, it has not been possible so far to identify a specific pathogen responsible for any form of periodontitis. Therefore, more complex models of pathogenesis, invoking mixed and/or sequential infections, have been plausibly proposed (Caldwell et al., 1997; Page, 1995). Nevertheless, the specific pathogen model cannot be dismissed, since numerous bacterial species present in dental plaque have yet to be evaluated in epidemiological studies and because 
within any species clones of widely differing virulence may exist (Choi et al., 1994; Haffajee \& Socransky, 1994; Riviere et al., 1991).

Spirochaetes are prominent in subgingival plaque of many periodontitis patients. At least 25 species-level phylotypes of oral treponemes have been recognized (Choi et al., 1994; Paster et al., 1998) and their clinical prevalence has been studied using specific $16 \mathrm{~S}$ rDNA oligonucleotide probes (Moter et al., 1998). However, most of their phenotypic characteristics are unknown, since to date only seven species have been studied extensively in culture (Paster et al., 1998; Umemoto et al., 1997; Wyss et al., 1996, 1997). Among these, the proteolytic activity of Treponema denticola is the physiological activity most widely accepted as having pathogenetic potential (Holt \& Bramanti, 1991).

Using novel techniques for the cultivation of fastidious anaerobes from subgingival plaque, we have isolated large numbers of oral spirochaetes, including members of the recently described species Treponema maltophilum and Treponema amylovorum (Paster et al., 1998; Wyss et al., 1996, 1997). We now describe eight small spirochaetal isolates possessing prominent phospholipase A (PLA) and phospholipase C (PLC) activities that form a phenotypically distinct homogeneous group and represent a novel genotype, as defined by qualitative dot-blot DNA-DNA hybridization and 16S rRNA sequencing. Association of this group with disease was more pronounced in patients with rapidly progressive periodontitis than in those with adult periodontitis. We propose the designation of a new species, Treponema lecithinolyticum sp. nov., with strains OMZ $684^{\mathrm{T}}$ and $\mathrm{OMZ} 685$ as type and reference strains, respectively.

\section{METHODS}

Bacteria. Reference strains were obtained and maintained as described previously (Wyss et al., 1996). Novel isolates were named as follows: the first two letters designate patient origin, the third position designates plaque sample (e.g. FO1DAA and FOC6C1 were isolated from two different plaque samples of the same patient; BL2A and BL2B are isolates from the same plaque sample; see Table 1). Two of the new isolates, maintained in medium OMIZ-Pat-w/oPC, were designated type and reference strains and deposited in the ATCC: the proposed type strain is ATCC $700332^{\mathrm{T}}$ $\left(=\mathrm{PFB} 4 \mathrm{G}^{\mathrm{T}}=\mathrm{OMZ} 684^{\mathrm{T}}\right)$ and the proposed reference strain is ATCC 700333 (= MH1DD = OMZ 685).

Culture media. For the cultivation of lecithinolytic treponemes, medium OMIZ-Pat (Wyss et al., 1996) was prepared without dipalmitoyl phosphatidylcholine (OMIZ-Pat-w/o PC). For all other strains, OMIZ-Pat and OMIZ-Patw/oPC could be used interchangeably.

\section{Enzyme activities}

For the determination of enzyme activities, cells from actively growing cultures were centrifuged and resuspended as recommended for Api Zym tests. Aliquots of these suspensions were added to substrates as indicated and incubated aerobically at $35^{\circ} \mathrm{C}$.
Api Zym tests. These tests were performed as described previously (Wyss et al., 1996), except that cells were grown in OMIZ-Pat-w/oPC.

Fluorogenic assay for sialidase. The fluorogenic sialidase substrate 4-methylumbelliferyl $\mathrm{N}$-acetylneuraminic acid (MUNANA; Sigma), dissolved at $100 \mu \mathrm{g} \mathrm{m}^{-1}$ in buffer $\mathrm{B}$ of Kurioka \& Matsuda (1976), was mixed with an equal volume of cell suspension and product formation was determined after $4 \mathrm{~h}$ with a Cytofluor 2350 fluorimeter (Millipore) set at excitation and emission wavelengths of 360 and $460 \mathrm{~nm}$, respectively.

Assays for PLC. The turbidimetric assay of Jolivet-Reynaud et al. (1988), with egg lecithin (Merck) or synthetic dipalmitoyl phosphatidylcholine (Sigma) as substrate, was modified by substituting desoxycholate for cholate in order to disperse the lecithin. PLC from Clostridium perfringens (Sigma) was used as a positive control. A spectrophotometric assay using a water-soluble substrate analogue, $p$-nitrophenyl phosphorylcholine (pNP-PC; Sigma), was performed as described by Kurioka \& Matsuda (1976). A fluorometric assay was developed using a 1:1 mixture of cell suspension and a solution of $10 \mu \mathrm{g} \mathrm{ml}^{-1}$ of the water-soluble substrate analogue 4-methylumbelliferyl phosphocholine (MU-PC; Molecular Probes) in buffer B of Kurioka \& Matsuda (1976); product formation was determined after $4 \mathrm{~h}$ with a Cytofluor 2350 fluorimeter (Millipore) set at excitation and emission wavelengths of 360 and $460 \mathrm{~nm}$, respectively (Freeman et al., 1985).

Assays for PLA. Phospholipase activity was identified by TLC product analysis (Tigyi \& Miledi, 1992) after incubation for $24 \mathrm{~h}$ of $50 \mu \mathrm{l}$ cell suspension (or reference phospholipase) with $2 \mathrm{ml}$ of $5 \mathrm{mg} \mathrm{ml}^{-1}$ synthetic dipalmitoyl lecithin in buffer B of Kurioka \& Matsuda (1976) supplemented with $5 \mathrm{mg}$ desoxycholate $\mathrm{ml}^{-1}$. Reference lipids, including palmitoyl lysolecithin and dipalmitin, were obtained from Sigma. Phospholipase A 2 from Crotalus adamantus (Sigma) was used as a positive control.

A more convenient screening of PLA activity was accomplished using a fluorochrome assay with the synthetic substrate analogue 1,2-bis-(4,4-difluoro-5,7-dimethyl-4bora-3a,4a-diaza-s-indacene-3-undecanoyl)-sn-glycero-3phosphocholine (Hendrickson, 1994) (Bis-BODIPY; Molecular Probes) dissolved $\left(2 \mu \mathrm{g} \mathrm{ml}^{-1}\right)$ in buffer B of Kurioka \& Matsuda (1976) supplemented with $10 \mu \mathrm{g}$ cholesterol $\mathrm{ml}^{-1}$. A 1:1 mixture of cell suspension and substrate solution was incubated for $4 \mathrm{~h}$. BODIPY-acyl release through cleavage by PLA leads to increased fluorescence, which was measured using a Cytofluor 2350 fluorimeter set at excitation and emission wavelengths of 485 and $530 \mathrm{~nm}$, respectively.

Qualitative whole DNA-DNA dot-blot hybridization. Digoxigenin (DIG) labelling and detection of strain OMZ $684^{\mathrm{T}}$ DNA was performed using a commercial kit (Boehringer) according to the manufacturer's instructions. Dot hybridization at $68^{\circ} \mathrm{C}$ to cellular DNA denatured with $\mathrm{NaOH} /$ EDTA on grid filters (Millipore HAWG $047 \mathrm{S3}$ ) with a stringent wash in $0.2 \times \mathrm{SSC}$ containing $0.1 \% \mathrm{SDS}$ was performed according to the method of Burnens \& Nicolet (1992).

Assay for haemolytic activity. Haemolysis was determined either by the addition of $2 \%$ washed human erythrocytes plus $1.5 \%$ agarose to OMIZ-Pat-w/oPC or in a 96-well plate assay according to Jolivet-Reynaud et al. (1988) using human erythrocytes.

Sugar stimulation of growth. These semi-quantitative tests were performed as described previously (Wyss, 1992; Wyss 
et al., 1996), but in media lacking dipalmitoyl phosphatidylcholine.

SDSPAGE gels and Western blots: These were done as described previously (Wyss et al., 1996) using extracts prepared from cells grown in OMIZ-Pat-w/oPC. Flagellins were detected as described previously (Wyss, 1998).

Limit dilution culture of plaque. This was performed as described previously (Wyss et al., 1996) with medium OMIZPat-w/oPC supplemented with rifampicin $\left(1 \mu \mathrm{g} \mathrm{ml}^{-1}\right)$ and fosfomycin $\left(100 \mu \mathrm{g} \mathrm{ml}^{-1}\right)$.

Electron microscopy. Specimen preparation was done as described previously (Wyss et al., 1996) using cells grown in OMIZ-Pat-w/oPC.

$16 S$ rDNA sequencing and phylogenetic analysis. Treponemes from $10 \mathrm{ml}$ cultures in OMIZ-Pat-w/oPC were pelleted by centrifugation and washed once in PBS. The pellet was resuspended in $400 \mu$ lysis buffer $(500 \mathrm{mM}$ Tris/ $\mathrm{HCl}, \mathrm{pH} 9 \cdot 0,20 \mathrm{mM}$ EDTA, $10 \mathrm{mM} \mathrm{NaCl}, 1 \%$ SDS) containing proteinase $\mathrm{K}$ (final concentration $200 \mu \mathrm{g} \mathrm{m}^{-1}$; Boehringer Mannheim) and incubated at $37^{\circ} \mathrm{C}$ for $2 \mathrm{~h}$. Phenol/chloroform extraction and all further steps were done as described previously (Choi et al., 1994). 16S rDNA was amplified using eubacterial universal primers, TPU1 $\left(5^{\prime}\right.$ AGAGTTTGATCMTGGCTCAG 3') and RTU8 (5' AAGGAGGTGATCCAKCCRCA 3'). The same primers were used for sequencing the PCR products by a modified Sanger dideoxynucleotide chain-termination method using Sequenase (USB) and a model 4000 LI-COR automated sequencer (MWG-Biotech) according to the manufacturers' instructions.

Phylogenetic analysis of 16S rRNA. The nearly complete $16 \mathrm{~S}$ rRNA sequences were compared with those of all sequences currently accessible from public databases (EMBL, GenBank) and private databases (Choi et al., 1994; Paster et al., 1991). A phylogenetic tree was constructed by using the TREECON software package (Jukes \& Cantor, 1969) and including all nucleotide positions for distance calculation. The neighbour-joining method of Saitou \& Nei (1987) was used and multiple base changes at single positions were corrected by the method of Jukes and Cantor (Van de Peer \& De Wachter, 1993).

\section{Epidemiological study}

Clinical samples. A total of 244 subgingival plaque specimens (200 specimens from deep periodontal pockets and 44 specimens from healthy control sites) from 53 patients suffering from rapidly progressive periodontitis (RPP) were collected as described previously (Moter et al., 1998). A further 325 specimens from previously untreated patients with adult periodontitis (AP) were investigated ( 268 samples from periodontal pockets plus 67 samples from unaffected sites from the same patients). Plaque samples were collected as described previously (Moter et al., 1998). Diagnoses of RPP and AP were made according to established criteria (Page et al., 1983).

DNA extraction and amplification. Aliquots of plaque suspensions were pelleted and bacteria were resuspended in $100 \mu l$ lysis buffer. Eubacterial amplification of $16 \mathrm{~S}$ rDNA was performed using universal primers TPU1 and RTU3 (5' GWATTACCGCGGCKGCTG $3^{\prime}$ ) as described previously (Moter et al., 1998).

Specific dot-blot hybridizations. After denaturation, PCR-amplified plaque material was spotted onto nylon membranes. Oligonucleotide probe TLECI ( 5 ' CACTCTCAGAAAGGAGCAAGCTCC $3^{\prime}$ ) was designed according to the phylogenetic tree retrieved from an earlier comparative $16 \mathrm{~S}$ rRNA analysis (Choi et al., 1994) and all 16S rDNA entries currently available at the EMBL and GenBank databases. The probe was labelled with DIG-ddUTP (Boehringer Mannheim). Bound probe was detected by chemiluminescence according to the manufacturer's recommendations. To adjust the hybridization specificity of probe TLECI, PCR-amplified 16S rDNA from 34 related and unrelated bacteria, including cultivable and uncultured treponemes as well as other oral micro-organisms, served as controls (Moter et al., 1998). Stringency was adjusted by varying the washing temperature and SSC concentration $(0 \cdot 1-5 \cdot 0 \times \mathrm{SSC})$ in the washing buffer $(1 \times \mathrm{SSC}$ is $0.15 \mathrm{M}$ $\mathrm{NaCl}, 0.015 \mathrm{M}$ sodium citrate, $0.2 \% \mathrm{SDS}$ ). The detection limit with cultured cells of strain OMZ $684^{\mathrm{T}}$ was in the range of 100 organisms, but this may differ with subgingival plaque material.

\section{RESULTS}

\section{Isolation from subgingival plaque}

During the screening of limit dilution cultures derived from subgingival plaque samples using medium OMIZ-Pat supplemented with rifampicin and fosfomycin (Wyss et al., 1996), we encountered a clone of small spirochaete, OMZ $684^{\mathrm{T}}$, that was difficult to subculture and that produced a notable precipitate. Analysis of the nutritional requirements of this unusual isolate revealed that its growth was inhibited by

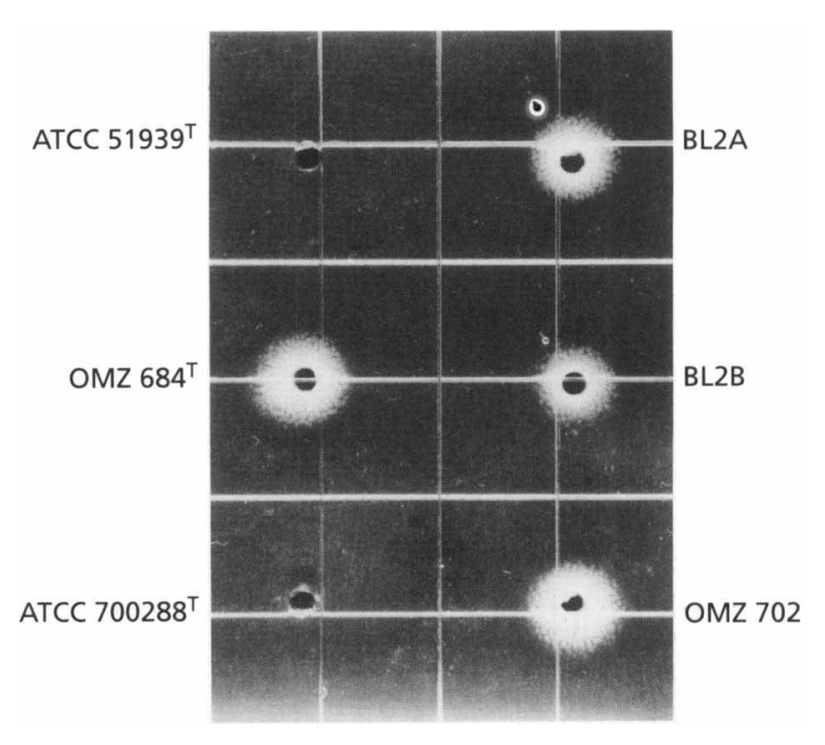

Fig. 1. PLC-dependent production of turbidity in lecithinagarose after $4 \mathrm{~h}$ aerobic incubation at $37^{\circ} \mathrm{C}$. Wells in lecithinagarose contained cell suspensions prepared as for the Api Zym tests of the strains indicated $(15 \mathrm{ml}$ agar per Integrid dish, grid size $13 \mathrm{~mm}$ ). Positive reactions, such as those seen for $O M Z$ $684^{\top}, B L 2 A, B L 2 B$ and $O M Z 702$, were also observed with the other six novel isolates (EL3M1A, FO1DAA, FOC6C1, HA2B, OMZ 685 and $M H 3 C$ ). Negative reactions, as shown here for $T$. maltophilum ATCC $51939^{\top}$ and $T$, amylovorum ATCC $700288^{\top}$, were seen with all other tested treponemes, ' $T$. vincentii' ATCC $35580, T$. denticola ATCC $35405^{\top}$, $T$. socranskii subsp. socranskii ATCC $35536^{\top}, T$. socranskii subsp. paredis ATCC $35535^{\top}, T$. socranskii subsp. buccale ATCC $35534^{\top}$ and Treponema pectinovorum ATCC $33768^{\top}$ 
Table 1. Origins of 10 oral Treponema isolates with lecithinolytic activity isolated from seven patients with refractory periodontitis

\begin{tabular}{|c|c|c|c|c|c|}
\hline Strain & $\begin{array}{c}\text { Patient } \\
\text { age/gender }\end{array}$ & Previous treatment & $\begin{array}{l}\text { Spirochaetes } \\
(\%)^{*}\end{array}$ & $\begin{array}{c}\text { Isolation } \\
\text { dilution } \\
\left(\log _{10}\right)\end{array}$ & $\begin{array}{c}\text { Other Treponema species } \\
\text { isolated from the } \\
\text { same sample }\end{array}$ \\
\hline BL2A & $60 / f$ & Mechanical & 73 & -7 & BL2B, $T$. denticola \\
\hline BL2B & $60 / f$ & Mechanical & 73 & -6 & $\begin{array}{l}\text { T. maltophilum (BL2A), } \\
\text { T. denticola }\end{array}$ \\
\hline EL3M1A & $20 / \mathrm{f}$ & Mechanical & 1 & -3 & $\begin{array}{l}\text { T. socranskii subsp. socranskii, } \\
\text { T. denticola }\end{array}$ \\
\hline FOIDAA & $43 / f$ & Mechanical & 17 & -3 & T. socranskii subsp. socranskii \\
\hline FOC6Cl & $43 / f$ & Mechanical & 48 & -6 & $\begin{array}{l}\text { T. socranskii subsp. buccale, } \\
\text { T. denticola, } T . \text { medium }\end{array}$ \\
\hline HA2B & $54 / \mathrm{m}$ & Mechanical & 62 & -4 & $\begin{array}{l}\text { T. amylovorum, } T \text {. denticola, } \\
T \text {. maltophilum }\end{array}$ \\
\hline OMZ 685 & $35 / f$ & $\begin{array}{l}\text { Metronidazole }+ \text { ciprofloxacin, } \\
3 \text { month control }\end{array}$ & 16 & -4 & $\begin{array}{l}\text { T. socranskii subsp. socranskii, } \\
\text { T. medium }\end{array}$ \\
\hline $\mathrm{MH} 3 \mathrm{C}$ & $35 / f$ & $\begin{array}{c}\text { Metronidazole }+ \text { ciprofloxacin, } \\
3 \text { month control }\end{array}$ & 45 & -4 & $\begin{array}{l}\text { 'T. socranskii subsp. 04', } \\
\text { T. maltophilum }\end{array}$ \\
\hline OMZ $684^{\mathrm{T}}$ & $33 / \mathrm{m}$ & Mechanical & 56 & -4 & $T$. pectinovorum \\
\hline OMZ 702 & $40 / \mathrm{f}$ & $\begin{array}{l}\text { Metronidazole }+ \text { ciprofloxacin, } \\
4 \text { month control }\end{array}$ & 8 & -4 & T. denticola \\
\hline
\end{tabular}

* The percentage of spirochaetes as a proportion of bacteria observed was determined by dark-field microscopy.

Table 2. Phospholipase activities and classification of oral spirochaetes

The 16S rRNA clusters to which each isolate belongs, as defined by Choi et al. (1994), are shown. ND, Not done.

\begin{tabular}{|c|c|c|c|c|c|c|c|}
\hline \multirow[t]{2}{*}{ Isolate } & \multirow{2}{*}{$\begin{array}{l}\text { 16S rRNA } \\
\text { cluster }\end{array}$} & \multirow[t]{2}{*}{ Haemolysis } & \multicolumn{5}{|c|}{ Relative enzyme activity (substrate) } \\
\hline & & & $\begin{array}{c}\text { PLC } \\
\text { (lecithin) }\end{array}$ & $\begin{array}{c}\text { PLC } \\
(\mathrm{pNP}-\mathrm{PC})\end{array}$ & $\begin{array}{c}\text { PLC } \\
\text { (MU-PC) }\end{array}$ & $\begin{array}{l}\text { PLA (Bis- } \\
\text { BODIPY) }\end{array}$ & $\begin{array}{c}\text { Sialidase } \\
\text { (MU-NANA) }\end{array}$ \\
\hline 'T. vincentii' OMZ 800 & 1 & - & 0 & 4 & 1 & 0 & 0 \\
\hline 'T. vincentii' ATCC 35580 & 1 & - & 0 & 8 & 9 & 0 & 0 \\
\hline T. medium $\mathrm{OMZ} 805$ & 2 & ND & 0 & 6 & 4 & 0 & 9 \\
\hline T. medium OMZ 806 & 2 & ND & 0 & 3 & 1 & 0 & 9 \\
\hline T. denticola ATCC $35405^{\mathrm{T}}$ & 11 & + & 0 & 5 & 4 & 0 & 9 \\
\hline T. denticola $\mathrm{BL} 2 \mathrm{C}$ & 11 & ND & 0 & 3 & 2 & 0 & 9 \\
\hline T. denticola $\mathrm{HA} 2 \mathrm{R} 12$ & 11 & ND & 0 & 7 & 8 & 0 & 9 \\
\hline T. maltophilum ATCC $51939^{\mathrm{T}}$ & 17 & - & 0 & 4 & 0 & 0 & 0 \\
\hline T. maltophilum ATCC 51941 & 17 & - & 0 & 6 & 2 & 0 & 0 \\
\hline T. maltophilum $\mathrm{BL} 2 \mathrm{~A}$ & 17 & ND & 9 & 9 & 1 & 0 & 0 \\
\hline T. maltophilum OMZ 702 & 17 & + & 9 & 9 & 2 & 0 & 0 \\
\hline T. lecithinolyticum OMZ 685 & 17 & + & 9 & 2 & 1 & 9 & 9 \\
\hline T. lecithinolyticum $\mathrm{OMZ} 684^{\mathrm{T}}$ & 17 & + & 9 & 3 & 2 & 9 & 9 \\
\hline T. lecithinolyticum BL2B & 17 & ND & 9 & 1 & 0 & 9 & 9 \\
\hline T. amylovorum ATCC $700288^{\mathrm{T}}$ & 19 & - & 0 & 0 & 0 & 0 & 3 \\
\hline
\end{tabular}

the lecithin contained in medium OMIZ-Pat and that precipitate formation depended on the presence of lecithin. OMZ $684^{\mathrm{T}}$ cells displayed a strong PLC activity in the turbidimetric test, which relies on the insolubility of the diacylglycerol product (Fig. 1). However, neither diacylglycerol nor phosphoryl- choline, the products of PLC action on lecithin, could reproduce the growth-inhibitory effect of lecithin. Growth inhibition was seen with palmitoyl lysolecithin, one of the products of PLA action on dipalmitoyl lecithin, but not with palmitic acid. TLC analysis of dipalmitoyl lecithin $\left(R_{F} 0 \cdot 5\right)$ incubated with 


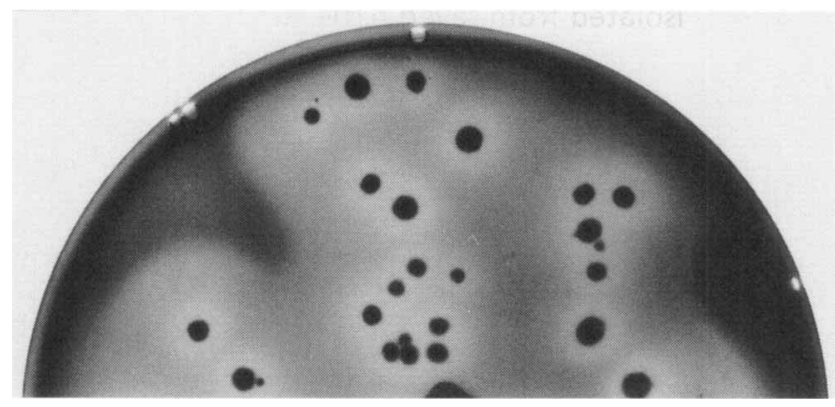

Fig. 2. Haemolytic zones around colonies of strain $O M Z 684^{\top}$ grown for $12 \mathrm{~d}$ on OMIZ-Pat-w/oPC agar with human erythrocytes in a $9 \mathrm{~cm}$ Petri dish.
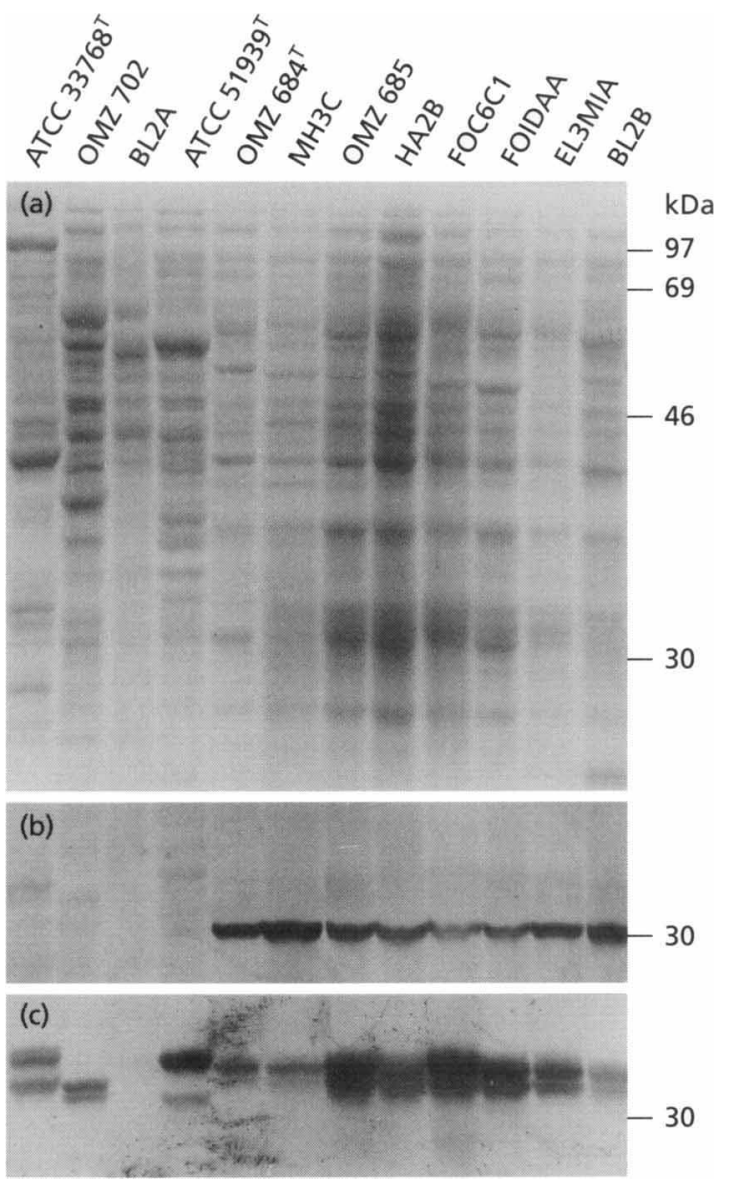

Fig. 3. Western blots of the 10 novel isolates and the type strains of $T$. maltophilum, ATCC $51939^{\top}$, and $T$. pectinovorum, ATCC $33768^{\top}$, after SDS-PAGE ( $10 \%$ gel) stained for protein (a), for a $\sim 30 \mathrm{kDa}$ OMZ 684 group-specific antigen (b) and for glycosylated flagellin (c) [same blot as (a), labelled after removal of the protein stain]. Numbers on the right indicate positions of molecular mass markers (in $\mathrm{kDa}$ ).

intact cells of strain OMZ $684^{\mathrm{T}}$ revealed the production of dipalmitin $\left(R_{F} 0.95\right)$ and palmitoyl lysolecithin $\left(R_{F}\right.$ $0 \cdot 25)$, demonstrating activities of both PLC and PLA (data not shown).
On the basis of this information, we omitted lecithin from the culture medium (OMIZ-Pat-w/oPC) and have now isolated and characterized a total of 10 strains with PLC activity from nine subgingival plaque samples from seven patients with refractory periodontitis that did not respond to scaling and root planing (or, in two patients, even to antibiotic treatment). From each of these samples, we could also isolate at least one other species of oral treponeme, and there appeared to be no obvious correlation between the percentage of spirochaetes in microscopically observed bacteria and the nominal plaque dilution at which treponemes were isolated (Table 1).

\section{Growth characteristics}

Growth of all 10 lecithinolytic strains was dependent on $N$-acetylglucosamine and was stimulated by Dribose; growth of eight of these strains, including OMZ $684^{\mathrm{T}}$, was also promoted by L-fucose and by Darabinose, whereas growth of two strains (OMZ 702 and BL2A) was inhibited by L-fucose. Growth of some strains was also enhanced by D-fructose (excluding OMZ 684 $4^{\mathrm{T}}$ ) and/or D-xylose (including OMZ 684 ${ }^{\mathrm{T}}$ ). Proliferation of all strains was independent of asialofetuin but was completely inhibited by the addition of $1 \%$ foetal bovine serum, whereas $1 \%$ human serum had growth-promoting activity.

\section{Enzyme activities}

All strains showed a strong PLC activity towards egg or synthetic lecithin (Fig. 1), while their activities towards PLC substrate analogues pNP-PC and MUPC differed considerably (Table 2). The results of the determination of further enzymic activities divided the 10 strains into two homogeneous groups: eight strains (OMZ 684 group; OMZ 684 ${ }^{\mathrm{T}}$ plus BL2A, EL3M1A, FO1DAA, FOC6C1, HA2B, OMZ 685 and MH3C) had not only PLC but also PLA activity, as indicated by the Bis-BODIPY fluorochrome assay (confirmation of this activity as PLA by TLC, by the production of lysolecithin from synthetic dipalmitoyl lecithin, was made for strains OMZ $684^{\mathrm{T}}$ and OMZ 685 only). These strains also showed strong activities for alkaline phosphatase, acid phosphatase, $\beta$-galactosidase, $\beta$ glucuronidase and $N$-acetyl- $\beta$-glucosaminidase and moderate activities for $\mathrm{C} 4$-esterase, $\mathrm{C} 8$-esterase, naphthol phosphohydrolase and $\alpha$-fucosidase. The three strains tested (OMZ 684 ${ }^{\mathrm{T}}$, OMZ 685 and BL2B) showed strong sialidase activity (Table 2).

The remaining two strains (OMZ 702 and BL2A) differed from the OMZ 684 group by the absence of PLA, $\beta$-glucuronidase and $N$-acetyl- $\beta$-glucosaminidase activities and by only weak to intermediate activities of alkaline phosphatase and $\beta$-glucuronidase. A weak $\alpha$-glucosidase activity was found in BL2A, only; no sialidase activity was detected (Table 2).

As shown in Table 2, representative strains of other cultivated oral treponemes, including type or other 


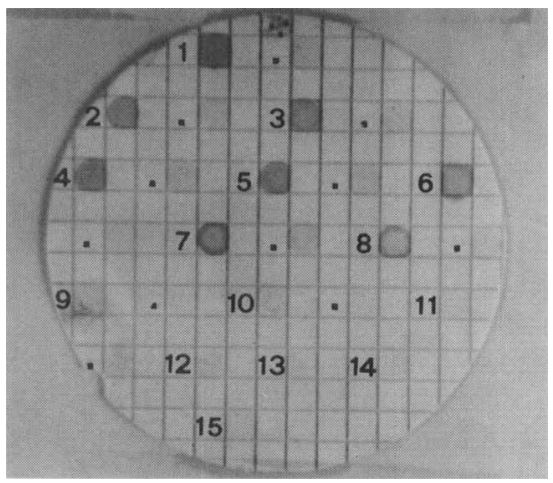

Fig. 4. Hybridization between DIG-labelled OMZ $684^{\top}$ DNA and lysates of cultured oral treponemes immobilized on nitrocellulose. $\mathrm{NaOH}$ cell lysates were spotted to the right of the numbered squares; $1: 10$ dilutions of lysates 1-11 were spotted to the right of squares marked with a dot. 1, OMZ $684^{\top} ; 2$ BL2B; 3, EL3M1A; 4, FO1DAA; 5, FOC6C1; 6, HA2B; 7 , OMZ 685; 8, MH3C; 9, BL2A; 10, OMZ 702; 11, T. maltophilum ATCC 51939'; 12, ' $T$. vincentii' ATCC 35580; 13, BL3G2 (a proteolytic treponeme clinical isolate); $14, T$. denticola ATCC $35405^{\top}, 15, T$. amylovorum ATCC $700288^{\top}$.

ATCC strains of $T$. amylovorum, $T$. denticola, $T$. maltophilum, Treponema socranskii subsp. socranskii and 'Treponema vincentii', showed differing activities towards the artificial hydrophilic PLC substrates pNP$\mathrm{PC}$ and MU-PC, but none in the turbidimetric assay for PLC; PLA activity detectable by the fluorochrome assay with Bis-BODIPY was found only in the OMZ 684 group.

\section{Haemolysis}

All five strains examined (FO1DAA, OMZ $684^{\mathrm{T}}, \mathrm{OMZ}$ 685 , OMZ 702 and BL2A) showed haemolytic activity when grown on solid OMIZ-Pat-w/oPC supplemented with $1 \%$ heat-inactivated human serum and $2 \%$ washed human erythrocytes (Fig. 2).

\section{Protein and antigen patterns}

For further phenotypic characterization and for comparison with other treponemes, protein and antigen profiles of SDS-PAGE-separated cell extracts were determined (Fig. 3). The results support the division of the ten lecithinolytic strains into two groups, with a dominant $\sim 30 \mathrm{kDa}$ antigen specific for the OMZ 684 group (Fig. 3b).

\section{Phylogenetic classification}

To estimate the genetic relationship among the novel isolates and towards known species of oral treponemes, we prepared DIG-labelled DNA of strain OMZ $684^{\mathrm{T}}$ by random-primed Klenow fragment synthesis. As shown in Fig. 4, the eight OMZ 684 group isolates were readily distinguished from the two other strains with PLC activity (OMZ 702 and BL2A) and represen-

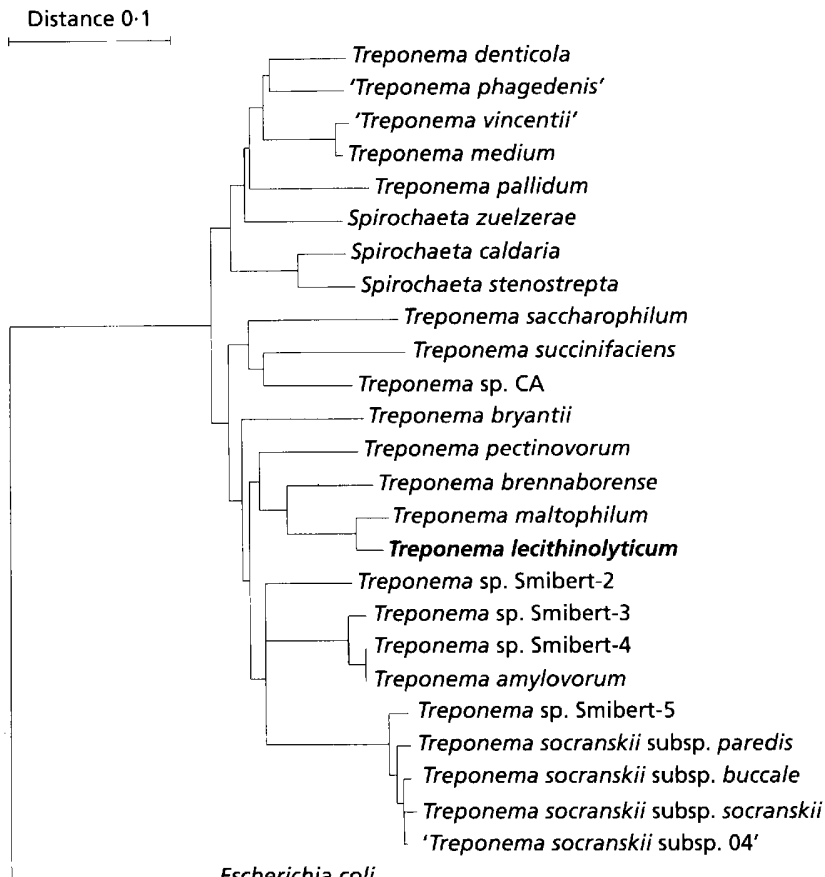

Fig. 5. Dendrogram based on comparative $16 \mathrm{~S}$ rRNA sequence analysis showing the phylogenetic position of group IV treponeme $T$. lecithinolyticum relative to other spirochaetes, with Escherichia coli as the outgroup. Bar indicates $10 \%$ difference in nucleotide sequence as determined by measuring the lengths of the horizontal lines connecting two sequences. The accession numbers of the sequences used for tree construction were: $T$. denticola M71236, 'Treponema phagedenis' M57739, ' $T$. vincentii' AF033309, Treponema medium D85437, Treponema pallidum M34266, Spirochaeta zuelzerae M34265, Spirochaeta caldaria M71240, Spirochaeta stenostrepta M34264, Treponema saccharophilum M71238, Treponema sp. CA M59294, Treponema succinifaciens M57738, Treponema bryantii M57737, T. pectinovorum M71237, $T$. maltophilum X87140, T. lecithinolyticum OMZ 684 $4^{\top}$ X8139, Treponema brennaborense $\mathrm{Y} 16568$ (Schrank et al., 1999), Treponema sp. Smibert-2 AF033304, Treponema sp. Smibert-3 AF023044, Treponema sp. Smibert-4 AF023045, T. amylovorum Y09959, Treponema sp. Smibert-5 AF033303, T. socranskii subsp. paredis AF033307, T. socranskii subsp. buccale AF033305, T. socranskii subsp. socranskii AF033306, 'Treponema socranskii subsp. 04' AF033308, E. coli J01859.

tatives of other oral Treponema species. In a complementary experiment, DIG-labelled DNA of strain OMZ 702 hybridized to dots of the novel isolates $\mathrm{OMZ}$ 702 and BL2A as well as T. maltophilum ATCC $51939^{\mathrm{T}}$, but not to OMZ $684^{\mathrm{T}}$, OMZ 685 or representative strains of T. amylovorum, T. denticola or ' $T$. vincentii' (data not shown).

The nearly complete $16 \mathrm{~S}$ rRNA sequences of strains OMZ $684^{\mathrm{T}}$ and OMZ 702 were determined. The sequence of OMZ $684^{\mathrm{T}}$ showed $96.5 \%$ identity to its closest cultured relative, T. maltophilum ATCC $51939^{\mathrm{T}}$, but also clustered in phylogenetic group IV according to the classification scheme of Choi et al. (1994) (Fig. 5). In contrast, the sequence of OMZ 702 showed $99.5 \%$ identity to that of $T$. maltophilum. On 


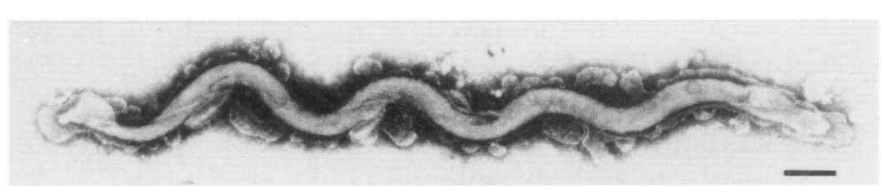

Fig. 6. Electron micrograph of a negative-contrasted cell of strain OMZ $684^{\top}$. Bar, $0.2 \mu \mathrm{m}$.

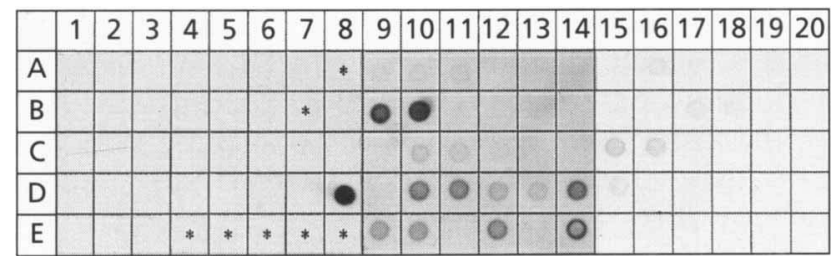

Fig. 7. Dot-blot hybridizations with $\mathrm{OMZ} 684^{\top}$-specific probe TLECI. In columns 1-8, PCR products of the following strains, kindly provided by R. Mutters ${ }^{1}$ (Marburg) and B. Wilske ${ }^{2}$ (München) where indicated, were applied: Actinobacillus actinomycetemcomitans ${ }^{1}$ MCCM 02638 (A1), Capnocytophaga gingivalis $^{1}$ MCCM 00858 (A2), Capnocytophaga ochracea ${ }^{1}$ MCCM 00238 (A3), Eubacterium lentum ${ }^{1}$ ATCC $25559^{\top}$ (A4), Fusobacterium nucleatum ${ }^{1}$ ATCC $25586^{\top}$ (A5), Porphyromonas gingivalis ${ }^{1}$ ATCC 33277 (A6), Prevotella intermedia' ${ }^{1}$ MCCM 00407 (A7); ' $T$. vincentii' ATCC 35580 (B1), $T$. denticola ATCC $35405^{\top}$ (B2), $T$. socranskii subsp. socranskii ATCC $35536^{\top}$ (B3), $T$. socranskii subsp. buccale ATCC $35534^{\top}$ (B4), T. maltophilum ATCC $51939^{\top}$ (B5), 'T. phagedenis subsp. reiterii' ${ }^{2}$ (B6), clinical isolate, highest homology to clone NZM 3142 (B8), $T$. pectinovorum ATCC $33768^{\top}$ (E1), T. lecithinolyticum OMZ 684 (D8); recombinant clones: group I: NZM3D292 (C1), NZM3D464 (C5), NZM3112 (C6), NZM3142 (D2), NZM3147 (D4), NZM 3166 (D7); group II: NZM3106 (C7), NZM3158 (D6); group III: NZM3143 (D3), NZM3D298 (C3), NZM3D527 (C4); group IV: NZM3122 (C8), NZM3D505 (C2); group V: NZM3124 (D1), NZM3155 (D5); group VI: NZM3104 (E2); group VII: NZM3D384 (E3). In columns 9-14 and 15-20, PCR products from subgingival plaque samples of RPP and AP patients, respectively, were applied. TLECI does not detect treponemes of the $\mathrm{OMZ} 702$ group since the sequences differ at three positions. *, No sample applied.

the basis of partial sequences ( $628 \mathrm{bp}$ ), the sequence of non-motile isolate BL2A showed $99 \cdot 5 \%$ identity to that of OMZ 702; these two strains are therefore considered to belong to T. maltophilum (Table 2).

\section{Morphology}

As shown in Fig. 6 for strain OMZ $684^{\mathrm{T}}$, nine of the lecithinolytic isolates are small spirochaetes with two endoflagella, one per pole, which sometimes overlap in the middle of the cell. The tenth isolate, BL2A, was observed in the initial well to form a floating, compact colony of non-motile cells. When streaked onto solid medium for recloning, all nine motile isolates formed fluffy subsurface colonies, whereas strain BL2A formed raised colonies that did not penetrate into the agar. The non-motile cells of strain BL2A are helically

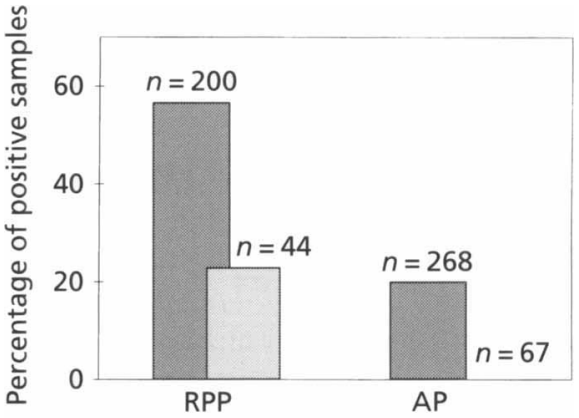

Fig. 8. Presence of $T$. lecithinolyticum OMZ $684^{\top}$ complementary sequences in subgingival plaque specimens from periodontal pockets (dark bars) or control sites (light bars) of periodontitis patients, analysed by dot-blot hybridization of PCR-amplified samples using oligonucleotide probe TLECI.

coiled like the other novel isolates, but neither flagella nor Fla B proteins could be detected (Fig. 3c).

\section{Epidemiology}

To assess the prevalence of the novel OMZ 684 group strains in periodontitis patients, dot-blot hybridizations were performed with an OMZ 684specific probe (TLECI). OMZ 684 group treponemes were detected in both patient groups (Fig. 7). However, the novel species was detected more frequently in deep periodontal pockets from RPP patients $(56.5 \%)$ than from AP patients $(19.8 \%)$. Only $22.7 \%$ in RPP patients and $0 \%$ in AP patients of the respective control sites were TLECI-positive (Fig. 8).

\section{DISCUSSION}

Numerous previously undetected bacterial species have been revealed in all natural environments that have been investigated using refined molecular biological techniques. However, these techniques provide no information regarding the expected phenotypes and therefore the possible biological roles of these unknown species. Here, we report the isolation and phenotypical characterization of a group of oral treponemes, the presence of which had hitherto only been inferred from the detection of 16S rRNA in dental plaque of a periodontitis patient (Choi et al., 1994). Very recently, Paster et al. (1998) identified strains of T. maltophilum (Smibert-1), T. amylovorum (Smibert-4) and three new species (Smibert-2, -3 and -5 ) in the Smibert culture collection of oral treponemes by phylogenetic analysis; however, they postponed definitive species description because of insufficient phenotypic data. As shown in Fig. 5, these are all phylogenetically distant from OMZ $684^{\mathrm{T}}$. This raises the number of cultured species of oral treponemes to 11 but still leaves the majority of known phylotypes to be isolated in vitro. 


\section{Phospholipase activity}

To our knowledge, the eight novel isolates are the first bacteria reported to show sufficient PLA activity to be detected with intact cells. Low levels detected in concentrated extracts of other bacteria are assumed to function in the turnover of cellular lipids. Previously reported microbial PLAs include a membraneassociated PLA of Campylobacter coli that may be involved in haemolysis (Grant et al., 1997), an outermembrane PLA of Enterobacteriaceae required for secretion of bacteriocins (Merck et al., 1997) and a PLA activity of Helicobacter pylori that may help this organism to reach the gastric epithelium (Slomiany et al., 1992).

In contrast, strong PLC activity is widely distributed amongst bacteria and is recognized as an important virulence factor (Titball, 1993). Our novel isolates are the first oral treponemes to show activity in the turbidimetric PLC assay, as used for the $\alpha$-toxin of Clostridium perfringens (Jolivet-Reynaud et al., 1988), although all strains except $T$. amylovorum hydrolysed the hydrophilic PLC substrate analogue pNP-PC (Table 2; Siboo et al., 1989). This latter activity has been purified from $T$. denticola on a lecithin-affinity matrix (Chan et al., 1991), suggesting that it is not simply due to a general phosphodiesterase; its specificity may be towards a phospholipid different from lecithin or its activity may be sensitive to the conditions of the turbidimetric assay.

\section{Growth inhibition}

Caution is essential with regard to results concerning environmental conditions required for growth of treponemes. Growth inhibition of the novel isolates by addition of $1 \%$ foetal calf serum to OMIZ-Pat medium is in line with previous results for T. socranskii (Wyss, 1992), T. maltophilum (Wyss et al., 1996) and T. amylovorum (Wyss et al., 1997) but contradicts results obtained in other culture systems (Smibert et al., 1984) and is contrary to physiological expectations. Similarly, the toxic effects of lysolecithin seen here and in other in vitro systems may be neutralized in vivo. This is suggested by the observation that this phospholipid is the only lipid consumed by Borrelia hermsii (Pickett \& Kelly, 1974) and several Treponema species (Trevathan et al., 1982).

\section{Role of phospholipase activity in vivo}

The physiological target of the strong activities of both PLC and PLA expressed by the novel isolates is most likely a component of the vertebrate host, since no such activity seems to be required for lipid metabolism by other treponemes. Direct action on host cell membranes may increase the local availability of nutrients and lead to enhanced tissue invasion by treponemes. The resulting production of potent regulators of eukaryote cell metabolism and inflammation such as ceramide, diglycerides, lysolecithin, arachi- donic acid and platelet-activating factor (Divecha \& Irvine, 1995; Prescott et al., 1990; Serhan et al., 1996; Songer, 1997; Titball, 1993) as well as the release of processed antigens from accessory cells is likely to affect host physiology severely (Falo et al., 1987).

Furthermore, in the subgingival niche there is ample opportunity for ecologically important interactions between host and the complex microbiota. These include the enhancement of cell damage through phospholipase action by strongly proteolytic organisms like $T$. denticola, Bacteroides forsythus, Porphyromonas gingivalis and Capnocytophaga species, which all rank high in the list of suspected periodonto-pathogens (Haffajee \& Socransky, 1994), or the cohaemolytic activity of phospholipase with Christie-Atkins-Munch-Petersen (CAMP)-active bacteria (Frey et al., 1989).

\section{Taxonomic position}

The strong PLC activity of the 10 clinical isolates reported in this study clearly separates them from all previously studied oral treponemes. On the basis of phylogenetic and additional phenotypic data, however, they represent two distinct groups, both located within group IV according to Choi et al. (1994) (Fig. 5). The larger group represented by OMZ $684^{\mathrm{T}}$ comprises eight strains and is phenotypically and genotypically homogeneous. Therefore, we propose group OMZ 684 organisms as a novel species, Treponema lecithinolyticum sp. nov.

The remaining two isolates, one of which lacked endoflagella since its primary isolation, are phylogenetically closely related to T. maltophilum, although previously described strains of that species are not known to display PLC activity (Paster et al., 1998; Wyss et al., 1996).

Isolation of novel organisms from complex microbial consortia not only allows their phenotypic and phylogenetic characterization but also serves in the development and validation of cultivation-independent methods for epidemiological studies on the aetiology of periodontal diseases.

\section{Epidemiology}

The primary aim of our cultural studies was to gain a view of the physiological diversity of oral treponemes. The data summarized in Table 1 confirm previous experience, that cultural analysis is unlikely to give an adequate quantitative picture of the spirochaetal population of plaque samples. Nevertheless, it may be noted that we also recovered proteolytic $T$. denticola from six of the nine plaque samples yielding PLC-active isolates.

Only patients of strictly characterized status were included in the clinical studies on AP and RPP using culture-independent methods. The results of this and a previous report (Moter et al., 1998) provide evidence 
for an association of group IV treponemes with AP and even more clearly with RPP. The association of $T$. denticola with specific forms of periodontitis appeared less pronounced than in previous studies (Riviere et al., 1992). The same 244 RPP plaque samples have been analysed in this and a previous study (Moter et al., 1998); of the 217 samples containing TREIV-complementary sequences, both $T$. maltophilum and $T$. lecithinolyticum were detected in 69 plaque samples, whereas neither of these two phylotypes were detected in 64 of the plaque samples. These latter samples may contain other as yet uncultured members of phylotype group IV.

In conclusion, our physiological and molecular epidemiological data suggest that small PLA- and PLCactive oral treponemes, comprising the proposed novel species $T$. lecithinolyticum, may contribute to the development and/or progression of RPP and, to a lesser degree, of AP.

\section{Description of Treponema lecithinolyticum sp. nov.}

Treponema lecithinolyticum (le.ci.thi.no.ly'ti.cum. Gr. $\mathrm{n}$. lekithos egg yolk; Gr. v. lytikos able to loose, dissolve; M.L. adj. lecithinolyticum effecting the breakdown of egg yolk).

An obligately anaerobic, helically coiled, motile treponeme. Cells are approximately $5 \times 0.15 \mu \mathrm{m}$, with a wavelength of $0.7 \mu \mathrm{m}$ and an amplitude of $0.3 \mu \mathrm{m}$. They contain two periplasmic flagella, one originating at each cell end and overlapping in the central region of the cell. In liquid media, flexing and rotation of cells does not appear to result in directional motility. However, in media of higher viscosity, or when cells creep along a surface, translational movement is readily detectable. Cells can be stored frozen (liquid nitrogen or mechanical freezer) in OMIZ-Pat-w/oPC medium supplemented with $10-20 \%$ glycerol.

When streaked onto OMIZ-Pat-w/oPC agarose, $T$. lecithinolyticum forms off-white, diffuse subsurface colonies up to $3 \mathrm{~mm}$ in diameter within $7 \mathrm{~d}$ incubation at $37^{\circ} \mathrm{C}$. T. lecithinolyticum does not grow in the chemically defined medium OMIZ-W1, but requires addition of yeast extract and/or Neopeptone (or fractions thereof). Growth is inhibited by lecithin, which must be omitted from the media formulation (OMIZ-Pat-w/oPC). Growth is strictly dependent on $\mathrm{N}$-acetylglucosamine and is strongly enhanced by further addition of D-arabinose, L-fucose or D-ribose; some strains also respond to $\mathrm{D}$-fructose (excluding OMZ 684 $4^{\mathrm{T}}$ ) and /or to D-xylose (including OMZ 684 ${ }^{\mathrm{T}}$ ). Growth is not influenced by L-arabinose, D-cellobiose, D-fucose, D-galactose, D-galacturonic acid, D-glucose, D-glucuronic acid, D-lactose, D-maltose, D-mannitol, D-melibiose, L-rhamnose, L-sorbose, D-sucrose, Dtrehalose or L-xylose. Heat-inactivated human serum $(1 \% \mathrm{v} / \mathrm{v})$ is tolerated or stimulatory, whereas $1 \%$ foetal calf serum is completely inhibitory. All strains are resistant to rifampicin $\left(1 \mu \mathrm{g} \mathrm{ml}^{-1}\right)$ and fosfomycin $\left(100 \mu \mathrm{g} \mathrm{ml}^{-1}\right)$.
In all eight isolates, activities of alkaline phosphatase, acid phosphatase, $\beta$-galactosidase, $\beta$-glucuronidase, $N$-acetyl- $\beta$-glucosaminidase, phospholipase $\mathrm{A}$ and phospholipase $\mathrm{C}$ are prominent, whereas only intermediate activities of C4-esterase, C8-esterase, naphthol phosphohydrolase and $\alpha$-fucosidase are expressed. Catalase is not produced. OMZ $684^{\mathrm{T}}, \mathrm{OMZ}$ 685 and BL2B have strong sialidase activity (the other five strains were not tested).

$T$. lecithinolyticum is phylogenetically distinct from other cultivable treponemes on the basis of its $16 \mathrm{~S}$ rRNA sequence. Protein and antigen patterns (SDSPAGE) are also readily distinguished from those of other cultivable treponemes, though more conventional criteria may suffice to distinguish it from the seven previously characterized oral spirochaetes. Simultaneous expression of strong activities of phospholipase $\mathrm{C}$, phospholipase $\mathrm{A}$, alkaline phosphatase, acid phosphatase, $\beta$-galactosidase, $\beta$-glucuronidase, $N$ acetyl- $\beta$-glucosaminidase and sialidase and intermediate activities of $\mathrm{C} 4$-esterase, C8-esterase, naphthol phosphohydrolase and $\alpha$-fucosidase distinguish $T$. lecithinolyticum from all other oral spirochaetes. Size, flagellation and growth characteristics additionally distinguish it from $T$. amylovorum, $T$. denticola, $T$. medium and ' $T$. vincentii'. Finally, $T$. lecithinolyticum is phenotypically distinguished from the two other lecithinolytic isolates described in this report, $\mathrm{OMZ}$ 702 and BL2A (which are phylogenetically classified as $T$. maltophilum), by its protein profile after SDS-PAGE, by a prominent antigen of $\sim 30 \mathrm{kDa}$ and by activities of phospholipase $\mathrm{A}$, sialidase, $\beta$ glucuronidase and $N$-acetyl- $\beta$-glucosaminidase.

$T$. lecithinolyticum has thus far been detected only in human subgingival plaque, with a strong association suggested for diseased versus control sites in patients with adult periodontitis and rapidly progressive periodontitis. Strains OMZ $684^{\mathrm{T}}$ and $\mathrm{OMZ}$ 685, isolated from subgingival plaque of human deep periodontal lesions, have been designated as type and reference strains and deposited under accession numbers ATCC $700332^{\mathrm{T}}$ and ATCC 700333 , respectively.

\section{ACKNOWLEDGEMENTS}

We thank C. Weiss, V. Zängerle and M. Kachler for expert technical assistance and $\mathrm{S}$. Shapiro for critical review of the manuscript. We also thank two anonymous reviewers for constructive comments. This work was supported in part by a grant to U.B.G. from the Deutsches Bundesministerium für Bildung und Forschung.

\section{REFERENCES}

Burnens, A. P. \& Nicolet, J. (1992). Detection of Campylobacter upsaliensis in diarrheic dogs and cats, using a selective medium with cefoperazone. Am J Vet Res 53, 48-51.

Caldwell, D. E., Atuku, E., Wilkie, D. C., Wivcharuk, K.P., Karthikeyan, S., Korber, D. R., Schmid, D. F. \& Wolfaardt, G. M. 
(1997). Germ theory vs. community theory in understanding and controlling the proliferation of biofilms. Adv Dent Res 11, 4-13.

Chan, E. C. S., Siboo, I. R. \& Siboo, R. (1991). Purification of phospholipase $\mathrm{C}$ by hydrophobic interaction affinity chromatography. J Chromatogr 568, 85-92.

Choi, B.-K., Paster, B. J., Dewhirst, F. E. \& Göbel, U. B. (1994). Diversity of cultivable and uncultivable oral spirochetes from a patient with severe destructive periodontitis. Infect Immun 62, 1889-1895.

Divecha, N. \& Irvine, R. F. (1995). Phospholipid signaling. Cell 80, 269-278.

Falo, L. D., Jr, Haber, S. I., Herrmann, S., Benacerraf, B. \& Rock, K. L. (1987). Characterization of antigen association with accessory cells: specific removal of processed antigens from the cell surface by phospholipases. Proc Natl Acad Sci USA 84, $522-526$.

Freeman, S. J., Shankaran, P., Wolfe, L. S. \& Callahan, J. W. (1985). Phosphatidylcholine and 4-methylumbelliferyl phosphorylcholine hydrolysis by purified placental sphingomyelinase. Can $J$ Biochem Cell Biol 63, 272-277.

Frey, J., Perrin, J. \& Nicolet, J. (1989). Cloning and expression of a cohemolysin, the CAMP factor of Actinobacillus pleuropneumoniae. Infect Immun 57, 2050-2056.

Grant, K. A., Belandia, I. U., Dekker, N., Richardson, P. T. \& Park, S. F. (1997). Molecular characterization of $p l d A$, the structural gene for a phospholipase A from Campylobacter coli, and its contribution to cell-associated hemolysis. Infect Immun 65, 1172-1180.

Haffajee, A. D. \& Socransky, S. S. (1994). Microbial etiological agents of destructive periodontal diseases. Periodontol 20005 , 78-111.

Hendrickson, H. S. (1994). Fluorescence-based assays of lipases, phospholipases, and other lipolytic enzymes. Anal Biochem 219 , $1-8$.

Holt, S. C. \& Bramanti, T. E. (1991). Factors in virulence expression and their role in periodontal disease pathogenesis. Crit Rev Oral Biol Med 2, 177-281.

Jolivet-Reynaud, C., Moreau, H. \& Alouf, J. E. (1988). Assay methods for alpha toxin from Clostridium perfringens: phospholipase C. Methods Enzymol 165, 293-297.

Jukes, T. H. \& Cantor, C. R. (1969). Evolution of protein molecules. In Mammalian Protein Metabolism, pp. 21-132. Edited by H. N. Munro. New York: Academic Press.

Kurioka, S. \& Matsuda, M. (1976). Phospholipase C assay using p-nitrophenylphosphoryl-choline together with sorbitol and its application to studying the metal and detergent requirement of the enzyme. Anal Biochem 75, 281-289.

Merck, K. B., de Cock, H., Verheij, H. M. \& Tommassen, J. (1997). Topology of the outer membrane phospholipase A of Salmonella typhimurium. J Bacteriol 179, 3443-3450.

Moore, W. E. C., Moore, L. H., Ranney, R. R., Smibert, R. M., Burmeister, J. A. \& Schenkein, H. A. (1991). The microflora of periodontal sites showing active destructive progression. J Clin Periodontol 18, 729-739.

Moter, A., Hoenig, C., Choi, B.-K., Riep, B. \& Göbel, U. B. (1998). Molecular epidemiology of oral treponemes associated with periodontal disease. J Clin Microbiol 36, 1399-1403.

Page, R. C. (1995). Critical issues in periodontal research. $J$ Dent Res 74, 1118-1128.

Page, R. C., Altman, L. C., Ebersole, J. L., Vandesteen, G. E.,
Dahlberg, W. H., Williams, B. L. \& Osterberg, S. K. (1983). Rapidly progressive periodontitis. A distinct clinical condition. $J$ Periodontol 54, 197-209.

Paster, B. J., Dewhirst, F. E., Weisburg, W. G. \& 7 other authors (1991). Phylogenetic analysis of the spirochetes. J Bacteriol 173, 6101-6109.

Paster, B. J., Dewhirst, F. E., Coleman, B. C., Lau, C. N. \& Ericson, R. L. (1998). Phylogenetic analysis of cultivable oral treponemes from the Smibert collection. Int J Syst Bacteriol 48, 713-722.

Pickett, J. \& Kelly, R. (1974). Lipid catabolism of relapsing fever borreliae. Infect Immun 9, 279-285.

Prescott, S. M., Zimmerman, G. A. \& McIntyre, T. M. (1990). Platelet-activating factor. J Biol Chem 265, 17381-17384.

Riviere, G. R., Wagoner, M. A., Baker-Zander, S. A., Weisz, K. S., Adams, D. F., Simonson, L. \& Lukehart, S. A. (1991). Identification of spirochetes related to Treponema pallidum in necrotizing ulcerative gingivitis and chronic periodontitis. $N$ Engl $\mathrm{J} \mathrm{Med}$ 325, 539-543.

Riviere, G. R., Elliot, K. S., Adams, D. F., Simonson, L. G., Forgas, L. B., Nilius, A. M. \& Lukehart, S. A. (1992). Relative proportions of pathogen-related oral spirochetes (PROS) and Treponema denticola in supragingival and subgingival plaque from patients with periodontitis. J Periodontol 63, 131-136.

Saitou, N. \& Nei, M. (1987). The neighbor-joining method: a new method for reconstructing phylogenetic trees. Mol Biol Evol 4, 406-425.

Schrank, K., Choi, B.-K., Grund, S., Moter, A., Heuner, K., Nattermann, H. \& Göbel, U. B. (1999). Treponema brennaborense sp. nov., a novel spirochaete isolated from a dairy cow suffering from digital dermatitis. Int J Syst Bacteriol 49, 43-50.

Serhan, C. N., Haeggström, J. Z. \& Leslie, C. C. (1996). Lipid mediator networks in cell signaling: update and impact of cytokines. FASEB J 10, 1147-1158.

Siboo, R., al-Joburi, W., Gornitsky, M. \& Chan, E. C. S. (1989). Synthesis and secretion of phospholipase $\mathrm{C}$ by oral spirochetes. $J$ Clin Microbiol 27, 568-570.

Slomiany, B. L., Piotrowski, J. \& Slomiany, A. (1992). Effect of sucralfate on the degradation of human gastric mucus by Helicobacter pylori protease and lipases. Am J Gastroenterol 87 , 595-599.

Smibert, R. M., Johnson, J. L. \& Ranney, R. R. (1984). Treponema socranskii sp. nov., Treponema socranskii subsp. socranskii subsp. nov., Treponema socranskii subsp. buccale subsp. nov., and Treponema socranskii subsp. paredis subsp. nov. isolated from the human periodontia. Int J Syst Bacteriol 34, 457-462.

Socransky, S. S. \& Haffajee, A. D. (1991). Microbial mechanisms in the pathogenesis of destructive periodontal diseases: a critical assessment. J Periodontal Res 26, 195-212.

Songer, J. G. (1997). Bacterial phospholipases and their role in virulence. Trends Microbiol 5, 156-161.

Tigyi, G. \& Miledi, R. (1992). Lysophosphatidates bound to serum albumin activate membrane currents in Xenopus oocytes and neurite retraction in $\mathrm{PC} 12$ pheochromocytoma cells. $J$ Biol Chem 267, 21360-21367.

Titball, R. W. (1993). Bacterial phospholipases C. Microbiol Rev 57, 347-366.

Trevathan, C. A., Smibert, R. M. \& George, H. A. (1982). Lipid catabolism of cultivated treponemes. Can $J$ Microbiol 28, 672-678.

Umemoto, T., Nakazawa, F., Hoshino, E., Okada, K., Fukunaga, M. \& Namikawa, I. (1997). Treponema medium sp. nov., isolated 
from human subgingival dental plaque. Int $J$ Syst Bacteriol 47, 67-72.

Van de Peer, Y. \& De Wachter, R. (1993). TREECON: a software package for the construction and drawing of evolutionary trees. Comput Appl Biosci 9, 177-182.

Wyss, C. (1992). Growth of Porphyromonas gingivalis, Treponema denticola, $T$. pectinovorum, $T$. socranskii, and $T$. vincentii in a chemically defined medium. $J$ Clin Microbiol 30 , 2225-2229.

Wyss, C. (1998). Flagellins, but not endoflagellar sheath proteins, of Treponema pallidum and of pathogen-related oral spirochetes are glycosylated. Infect Immun 66, 5751-5754.

Wyss, C., Choi, B.-K., Schüpbach, P., Guggenheim, B. \& Göbel, U. B. (1996). Treponema maltophilum sp. nov., a small oral spirochete isolated from human periodontal lesions. Int J Syst Bacteriol 46, 745-752.

Wyss, C., Choi, B.-K., Schüpbach, P., Guggenheim, B. \& Göbel, U. B. (1997). Treponema amylovorum sp. nov., a saccharolytic spirochete of medium size isolated from an advanced human periodontal lesion. Int J Syst Bacteriol 47, 842-845. 